\title{
7/8 HLA Match
}

National Cancer Institute

\section{Source}

National Cancer Institute. 7/8 HLA Match. NCI Thesaurus. Code C158041.

Degree of HLA Match is $7 / 8$ alleles with a single HLA locus mismatch at HLA-A, - $B,-C$ or DRB1. 